\title{
The Effects of Educational Multimedia in Dictation and Its Role in Improving Dysgraphia in Students with Dictation Difficulty
}

\author{
Esmaeel Azimi \\ Tarbiat Modares University, Iran \\ Saeed Mousavipour \\ Arak University, Iran
}

\begin{abstract}
The purpose of the present research is to study the effects of educational multimedia in dictation and its role in improving dysgraphia in students with dictation difficulty. Research methodology is categorized as being quasi-experimental. The statistical population of the study includes students with dictation difficulty of the second grade of primary schools of Arak in the 2011-2012 academic year. The population (including 39 students) is selected through utilization of Poisson sampling procedure. From the designated sample, 20 members are selected to be put in the experiment group and the remaining 19 members are put in the control group. Clinical interview, dictation test, and Wechsler Intelligence Scale for Children- Revised (WISC-R) are utilized to distinguish students with dictation difficulty from normal-progress students in learning disability center. Dictation test for data compilation and Man-Whitney- Wilcoxon U-Test (MWW) for data analysis are used. The findings of the study depict that the level of improvement of dysgraphia of those students who rely on educational multimedia in dictation has a positive statistical significance in comparison with those who rely on normal educational procedures $(p<.001)$. Therefore, educational multimedia in dictation has a positive impact in improving dysgraphia in students with dictation difficulty.
\end{abstract}

Keywords: Educational multimedia; Dysgraphia; Special education; Dictation difficulty

\section{Introduction}

Learning to read and write has utmost importance for human beings. Therefore, a large portion of educational system of any country is devoted to designation of educational methods on reading and writing learning practices. In linguistic hierarchical system, writing acquires the least attention (Agha-Babayee, Malekpour, \& Abedi, 2011) and since it is considered to be an abstract activity, it is coped with serious difficulty by children. Writing is in direct correlation with lexical maintenance of topics, graphic manifestations, pictographic configuration of letters and words, effective utilization of stationeries and efficient memory (Savari, 2008). In the meantime there exist students with dysgraphia problems even with normal levels of physical, mental, and intellectual status.

Dysgraphia is one type of learning disability. In the 1980s, the National Joint Committee on Learning Disabilities (NJCLD) defines the term learning disability as: 
a heterogeneous group of disorders manifested by significant difficulties in the acquisition and use of listening, speaking, reading, writing, reasoning or mathematical abilities. These disorders are intrinsic to the individual and presumed to be due to Central Nervous System Dysfunction. Even though a learning disability may occur concomitantly with other handicapping conditions (e.g. sensory impairment, intellectual disability, social and emotional disturbance) or environmental influences (e.g. cultural differences, insufficient/inappropriate instruction, psychogenic factors) it is not the direct result of those conditions or influences.

The 2002 LD Roundtable produced the following definition:

"Concept of LD: Strong converging evidence supports the validity of the concept of specific learning disabilities (SLD). This evidence is particularly impressive because it converges across different indicators and methodologies. The central concept of SLD involves disorders of learning and cognition that are intrinsic to the individual. SLD are specific in the sense that these disorders each significantly affect a relatively narrow range of academic and performance outcomes. SLD may occur in combination with other disabling conditions, but they are not due primarily to other conditions, such as intellectual disability, behavioral disturbance, lack of opportunities to learn, or primary sensory deficits.

American Psychiatric Association (2013) in the DSM IV had placed an individual's learning disorder into one of three categories: Specific Reading Disorder, Specific Math Disorder and Disorders of Written Expression. Students with written expression disorder can be manifested into three categories: dysgraphia dysfunction in handwriting skills, spelling, and composition (Karimi, 2010). In order to sustain proper writing skills, there should be an elaborate interrelationship between the eyes and the hands (Learner, 1997, translated by Danesh, 2005). In order to acquire and master such an interrelationship, students should do certain exercises so that a certain level of correlation and harmony between their dynamic and visual skills can be materialized.

Specialized learning procedures are vital in assisting such students (Ghare-Khani \& Khaledian, 2009). Educational multimedia can utilize effective strategies in teaching dictation to students with dictation difficulties by relying on individual, interactive, and personal requirements of each student (Adam \& Tatnall, 2010).

Mayer (2001) in his cognitive theory of multimedia learning defines educational multimedia as follows: "An educational multimedia includes communication through utilization of words and graphics that will promote learning skills (p. 21)." He believes that the logical motif behind the utilization of educational multimedia is to exploit individual's cognitive capacity in information processing. However, simply adding words to pictures is not an effective way to achieve multimedia learning. The goal is to instructional media in light of how human mind works. This is the basis for Mayer's cognitive theory of multimedia learning. This theory proposes three main assumptions when it comes to learning with multimedia:

(1) There are two separate channels (auditory and visual) for processing information (sometimes referred to as Dual-Coding Theory);

(2) Each channel has a limited capacity (similar to Sweller's notion of Cognitive Load); Learning is an active process of selecting, organizing, and integrating information based upon prior knowledge. 
(3) Humans can only process a finite amount of information in a channel at a time, and they make sense of incoming information by actively creating mental representations.

Mayer also discusses the role of three memory stores: sensory (which receives stimuli and stores it for a very short time), working (where we actively process information to create mental constructs (or 'schema'), and long-term (the repository of all things learned). Mayer's cognitive theory of multimedia learning presents the idea that the brain does not interpret a multimedia presentation of words, pictures, and auditory information in a mutually exclusive fashion; rather, these elements are selected and organized dynamically to produce logical mental constructs. Furthermore, Mayer underscores the importance of learning (based upon the testing of content and demonstrating the successful transfer of knowledge) when new information is integrated with prior knowledge.

Design principles including providing coherent verbal, pictorial information, guiding the learners to select relevant words and images, and reducing the load for a single processing channel etc. can be entailed from this theory (Mayer, 2005).

A number of scholarly studies are carried out on the issue of effectuality of educational multimedia on learning disabilities. For example, Khana (2010) studied the effects of educational multimedia systems on learning skills of students with learning disabilities. He depicts that educational multimedia systems has a positive effectuality on learning skills of students with learning disabilities.

Gustafson, Fälth, Svensson, Tjus, and Heimann (2011) found that a good combination of computerized and non-computerized training can be more effective on reading ability than each of the methods alone.

Malekian and Akhundi (2010) in "The Effects of Educational Multimedia in Dictation Improvement of Exceptional Students with Dictation Difficulty", studied 30 students with dictation difficulty and deduced that educational multimedia has significantly improved such students' dictation disability. Baezzat (2010) in "The Role of Word Processor and Self-Testing Strategies in Improvement of Dictation Difficulty of Third Grade Students of Primary Schools with Dysgraphia" concluded that there is a positive statistical variance between average value of dictation of those students who rely on computerized learning skills and those who rely on traditional and normal learning skills.

Kennedy, Deshler, and Lloyd (2013) found that the instructional multimedia model that was based on theoretical framework and educational methodology was more effective than the instructional multimedia model without such basis.

The aforementioned studies emphasize general learning skills of students with dictation difficulty and do not focus on minor background problems such as dysgraphia. In the present study, it is attempted to focus on deficiencies of prior studies. The practical importance of the current study is to represent multimedia software application in dictation, considering the prevalent educational regulations and visual and auditory retentions. Afterwards, its effectuality will be analyzed on the level improvement of dictation difficulty of second grade students of primary schools with dysgraphia. Therefore, the following research hypotheses are tested in this study: 
(1) Improvement of learning skills through utilization of educational multimedia in dictation has a significant impact on dictation difficulty of those students with learning disability and dysgraphia.

(2) Improvement of learning skills through utilization of educational multimedia in dictation has a significant impact on dictation difficulty of those students with learning disability and dysgraphia in comparison with prevalent educational methods and learning skills.

\section{Methodology}

This study is categorized under applied research and its data compilation method is categorized under experimental methodologies. The aim of the study is to test the hypotheses in two research groups through utilization of pretest and posttest.

Statistical Population and Sampling Procedure: The statistical population of the study includes students with dictation difficulty in the second grade of primary schools of Arak, who have been referred to learning disability centers in 2011-2012 academic year. The statistical population (including 39 students) is selected through utilization of Poisson sampling procedure. From the designated sample, 20 members are selected to be assigned in the experiment group and the remaining 19 members are assigned in the control group.

Methodology: Clinical interview, dictation test, and Wechsler Intelligence Scale for ChildrenRevised (WISC-R) are utilized to distinguish students with dictation difficulty from normal students in learning disability center. Furthermore, educational multimedia in dictation is utilized as the educational methodology of the study. Generally, research methodology of the study can be manifested as follows:

Wechsler Intelligence Scale for Children- Revised (WISC-R): In order to measure subjects' intelligence quotients (IQ) statistically, Wechsler Intelligence Scale for Children- Revised (WISCR) is utilized in this study. This test includes verbal intelligence (that is constituted of 6 subtests) and performative intelligence (that is constituted of 6 subtests). Through utilization of this test, three kinds of IQs can be manifested: Performative IQ (IQP), verbal IQ (IQV) and total IQ (IQT). In this study, IQT is of utmost importance, since its validity is of utmost scholarly authenticity. Wechsler' reported average rate of internal consistency (1974) is appointed for all 11 age groups as follows: 0/96 as IQT, 0/94 as IQV and 0/90 as IQP. Retesting stability in 30 days temporal period is appointed as follows: 0/95 as IQT, 0/93 as IQV and 0/90 as IQP. (Ramzani, 2000). This test is utilized to distinguish students with learning disability from students with mental disability in the learning disability center through statistical measuring of their IQs.

Clinical Interview: Subjects, who have refereed to the learning disability center, are interviewed clinically by psychological experts on the basis of criteria of the fourth edition of Diagnostic and Statistical Manual of Mental Disorders. The subjects are analyzed so that any auditory, visual or metal disability can be diagnosed. The results of the interviews are utilized so that it could be appointed whether the learning difficulties are generated due to learning disabilities or mental disabilities.

Dictation Achievement Test: In order to detect students with learning disabilities in dictation, a dictation test is utilized by the collaborative assistance of experts of the learning disability 
center on the basis of textbooks of the second grade of the primary school. According to the regulation of standard dictation tests, a dictation achievement test should consist of 120 words (Malekian \& Akhundi, 2010). In this study, dictation achievement test consists of 116 words. The words are selected in a way that students' prevalent dictation difficulties can be recognized. In order to achieve the perfect level of research validity, the test is scrutinized by a number of psychological experts and tutors of the learning disability center so that a number of educated changes can be implemented in the structure of the test. The reliability coefficient of the test is appointed 0/59 in its retesting stage. The analytic procedure of the study is designated in a way that after administrating the test, students with dysgraphia problem are given 1 and students without learning disability problem are given 0 . Afterwards, the average of each group is appointed between 0 and 1 .

Educational Multimedia in Dictation: The procedure for designing educational multimedia in dictation has occurred in the three phases of planning, application, and evaluation.

Planning: This educational multimedia software was developed mainly based on Indiana educational design. This model was used as a basis because: first the goal of building communication is clearly identified; second, the selection and identification of each of the components of the model is based on the previous components; third, as the design shows, information gained through evaluation can be used to modify and improve communication. In order to designate an effective educational multimedia in learning and teaching dictation without generating any social repercussions, it should be designed in an efficient educational framework (Pivec \& Pivec, 2011). Therefore, the standard regulations are compiled from various resources. Furthermore, educated views of educational technologists, educational planners, primary school tutors and psychological experts are utilized in the course of the designation of the multimedia software application so that educational regulations and standards can be met properly. Some of the considered regulations and standards are: Mayer multimedia presentation principles (Clark \& Mayer, 2011) proper implementation of educational materials from easy to difficult, concrete to abstract and administrative to nonadministrative materials. In the proposed software application of the study, a series of exercises and games are designated so that students' dysgraphia difficulty alongside with their dictation problems can be positively facilitated.

Application and Evaluation: Once developed, Dikte yar multimedia was offered to educational technologists for evaluation, and the software was modified based on their comments. Then the 20 subjects/students in the experimental group were required to work with the revised form the software. Next, the comments made by the students and trainers of the learning disability centers were collected to be incorporated in the final version the multimedia software. Finally, the formative evaluations carried out at three stages by the educational technologists, learning disability centers, and the students were utilized to improve and revise the software. At the end of the 15 sessions of dictation multimedia-based treatment which lasted for 15 weeks, the dysgraphia test was administered and the results were compared with the pretest to determine how the dysgraphia has been improved in the subjects.

Executive Method: After recognition of the experiment group and the control group, dictation achievement test is administered as the selected pretest. After the pretest, members of the experiment group are given four academic months to work with multimedia software application in dictation individually and under the supervision of the tutors of the learning 
disability center. Of course, tutors operate as educational conductors and supervisors rather than administrating like tutors, since the potentiality to analyze educational feedbacks is materialized in the system. In the same temporal period, traditional educational methods are implemented alongside with multimedia education in the learning disability center. 15 sessions are administrated in 15 weeks for both the experimental and control groups. The main concept of the sessions is to administer a series of educational exercises so that students' difficulty in dictation and dysgraphia can be met properly. Ultimately at the end of the 4 month period, the posttest achievement test in dictation is administered for both of the research groups.

Data Analysis: Wilcoxon non-parametric test and Man-Whitney $U$ test are utilized for dependant and independent binary groups respectively. In descriptive data analysis, statistical descriptive indexes such as average index, statistical frequency and standard deviation are utilized.

\section{Findings}

In descriptive data analysis, average index and standard deviation are utilized. The results of such utilization are depicted in Table 1.

Table 1. Descriptive Data of Control Group in Pretest and Posttest

\begin{tabular}{|c|c|c|c|c|c|}
\hline \multicolumn{2}{|c|}{$\begin{array}{l}\text { Control group } \\
\qquad(\mathrm{N}=19)\end{array}$} & \multicolumn{2}{|c|}{$\begin{array}{l}\text { Experimental group } \\
\qquad(\mathrm{N}=20)\end{array}$} & \multirow[b]{2}{*}{ Test } & \multirow[b]{2}{*}{ Variable } \\
\hline SD & $M$ & SD & $\mathrm{M}$ & & \\
\hline $0 / 37463$ & $0 / 8421$ & 0/41039 & $0 / 8000$ & Pretest & \\
\hline $0 / 50726$ & $0 / 5789$ & $0 / 36635$ & $0 / 1500$ & Posttest & Dysgraphia \\
\hline
\end{tabular}

In order to examine data normality, Kolmogorov-Smirnov test is utilized. The result of the test showed that the compiled scores did not exhibit normal modality. Therefore, in order to analyze research hypotheses, Wilcoxon non-parametric test and Man-Whitney $U$ test are utilized for dependent and independent binary groups respectively.

In order to analyze the first hypothesis of the study and compare the results of the pretest and the posttest in experiment group (educational multimedia in dictation), Wilcoxon test is utilized. The results are depicted in Table 2.

Table 2. Wilcoxon Test in the Experiment Group of Dysgraphia Difficulties

\begin{tabular}{|c|c|c|c|c|c|c|}
\hline$P$ & $Z$ & SD & $M$ & $\mathrm{n}$ & Groups & Variable \\
\hline \multirow{2}{*}{ 0/001 } & \multirow{2}{*}{$-3 / 606$} & $0 / 41039$ & $0 / 8000$ & 20 & Pretest & \multirow{2}{*}{ Dysgraphia } \\
\hline & & $0 / 36635$ & $0 / 1500$ & 20 & Posttest & \\
\hline
\end{tabular}

According to Table 2 , there is a significant variance between statistical values of pretest and posttest of the experiment group $(p=0 / 001, m=20, Z=-3 / 606)$. In other words, educational 
multimedia in dictation reduces dysgraphia difficulties among students. Therefore, the first research hypothesis is confirmed.

In order to analyze the second hypothesis of the study, Man-Whitney $U$ test is utilized with $0 / 05$ statistical significance. In the first stage, pretests are analyzed in the experiment and control groups. The results are depicted in Table 3.

Table 3. Comparison of Pretests of Control/Experiment Groups of Dysgraphia Difficulty

\begin{tabular}{|c|c|c|c|c|c|c|c|}
\hline$P$ & U & $\begin{array}{l}\text { Average } \\
\text { Rating }\end{array}$ & SD & $\mathrm{M}$ & $\mathrm{n}$ & Groups & Variable \\
\hline \multirow{2}{*}{$0 / 735$} & \multirow{2}{*}{$182 / 000$} & $19 / 60$ & 0/41039 & $0 / 8000$ & 20 & $\begin{array}{l}\text { Experiment } \\
\text { Group }\end{array}$ & \multirow{2}{*}{ Dysgraphia } \\
\hline & & $20 / 42$ & $0 / 37463$ & $0 / 8421$ & 19 & $\begin{array}{l}\text { Control } \\
\text { Group }\end{array}$ & \\
\hline
\end{tabular}

The comparison depicts that there is no significant variance in average rating between these groups: $(\mathrm{P}=0 / 735, \mathrm{n} 2=19, \mathrm{n} 1=20, \mathrm{U}=182 / 000)$. Furthermore, the results of posttests analysis are depicted in Table 4.

Table 4. Comparison of Posttests of Control/Experiment Groups of Dysgraphia Difficulty

\begin{tabular}{llllllll}
\hline$P$ & $U$ & $\begin{array}{l}\text { Average } \\
\text { Rating }\end{array}$ & SD & $M$ & $n$ & Groups & Variable \\
\hline $0 / 006$ & $15 / 92$ & $0 / 36635$ & $0 / 1500$ & 20 & $\begin{array}{l}\text { Experiment } \\
\text { Group }\end{array}$ & Dysgraphia \\
\hline
\end{tabular}

The comparison depicts that there is significant variance in average rating between these groups and therefore, the second hypothesis is confirmed: $(p=0 / 006, n 2=19, n 1=20$, $U=108 / 500)$.

\section{Discussion}

The practical importance of this study was to represent multimedia software application in dictation, considering the prevalent educational regulations and visual and auditory retentions. Afterwards, its effectuality was analyzed on the level improvement of dictation difficulty of second grade students of primary schools with dysgraphia. The results demonstrate that improvement of learning skills through utilization of educational multimedia in dictation has positive significance on dictation difficulty of those students with learning disability and dysgraphia in comparison with prevalent educational methods and learning skills.

The findings of this study are in direct correlation with those of Khana (2010), Malekian and Akhundi (2010), Baezzat (2010), and Gustafson, Fälth, Svensson, Tjus, and Heimann (2011) who propose positive effectuality of multimedia and computerized methodologies on improvement of learning disabilities. Results of the study appeared to be in agreement with Kennedy, 
Deshler, and Loyd's (2013) study which showed the success of educational multimedia software in educational planning.

Cognitively speaking, the rationale of the effectiveness of multimedia software lies in the fact that utmost use of information can be made when it enters the memory through auditory or visual channels. The perceived information is finally combined with previous knowledge through different channels and builds up new and stable information in the memory. This rationale is deeply rooted in the cognitive learning theory of multimedia (Mayer, 2001). It is interesting to point out that Coleman and Martin (2005), Magnan and Ecalle (2006), van Daal and van der Leij (1992), and Mioduser, Tur-Kaspa and Leitner (2000) have already investigated and established this logic. The present study as well backed up the logic through educational multimedia in dictation which makes the use of both auditory and visual channels. The other features of the multimedia software, which enable it to be cognitively effective, involve the use of senses for learning (Asgari \& Khaghani, 2009), increasing the level of concentration, attention, imaginativity, creativity, and performance of the students (Conati \& Zhao, 2004; Ketamo \& Suominen, 2010; Kim, Park, \& Baek, 2009; Tamjid-Tash, 2011). Computer-based multimedia with features like individualized training, adapting training to the needs and characteristics of the learners can play a significant role in helping students with learning disability to form knowledge and skills (Tatnall \& Adam). Dictation multimedia, taking advantage of the same features and making use of the potentials of general multimedia, can successfully remove the problems that students have with their the audio-visual memory.

Academic failures are the most prevalent outcomes in students with learning disabilities, causing them to become rude and angry. Educational multimedia methods facilitate learners' academic motivation (Asgari \& Khaghani, 2009).

Learning with multimedia is affected by emotional and motivational factors (Moreno, 2006). Through utilization of amiable graphics and pictorial elements, educational multimedia in dictation, learners' motivation will be facilitated, resulting in their attitude change towards learning and schooling systems. We tend to emphasize that, as Leutner (2014) has indicated, further studies should be carried out to investigate the impact of motivation on learning.

The logic behind educational multimedia is that when information is implemented in the memory through auditory and visual channels, the full potentiality of memory can be utilized. Ultimately, newly implemented information is combined with prior intellectual knowledge, resulting in generation of up-to-date and permanent knowledge structures. This logic has its roots in cognitive theory of multimedia learning procedures (Mayer, 2001).

\section{Conclusion}

The purpose of the present research was to study the effects of educational multimedia in dictation and its role in improving dysgraphia in students with dictation difficulty. The findings of the study demonstrated that the level of improvement of dysgraphia of the students who rely on educational multimedia in dictation has a positive statistical significance in comparison with those who rely on traditional (teacher-based) educational procedures. Most educational multimedia tools and applications consider learning disabilities in dictation generally; however, the software application used in the present research studies learning disability professionally and individually. Such a software application has a potential to resolve students' learning 
disability fundamentally. According to the results of this study, it is suggested that educational multimedia in dictation should be utilized in coping with students' learning disabilities in dictation. Furthermore, a number of other multimedia applications can be utilized in coping with other learning disabilities, considering the prevalent educational regulations and standards.

\section{References}

Adam, T. \& Tatnall A. (2010). Use of ICT to assist students with learning difficulties: An ActorNetwork Analysis. IFIP Advances in Information and Communication Technology, 324, 111.

Agha-Babayee, S., Malekpour, M., \& Abedi, A. (2011). A comparative study of performative factors in students with and without learning disabilities in dictation: A neuropsychological test of NEPSY. Clinical Psychology, 3(4), 35-40.

American Psychiatric Association. (2013). The diagnostic and statistical manual of mental disorders: DSM 5. bookpointUS.

Asgari, A. \& Khaghani, M. Z. (2009). Educational multimedia methodology. Journal of Exceptional Education Strategies, 2(4), 173-176.

Baezzat, F. (2010). The role of word processor and self-testing strategies in improvement of dictation difficulty of third grade students of primary schools with dysgraphia. Journal of Applied Psychology, 2(14), 58-71.

Clark, R. C. \& Mayer, R. E. (2011). E-learning and the science of instruction: Proven guidelines for consumers and designers of multimedia learning. New York: John Wiley \& Sons.

Coleman-Martin, M. B. ( 2005). Using computer-assisted instruction and the nonverbal reading approach to teach word identification. Focus Autism Other Developmental Disabilities, 20(2), 80-90. doi: 10.1177/10883576050200020401

Conati, C., Zhao, X. (2004). Building and evaluating an intelligent pedagogical agent to improve the effectiveness of an educational game. IUI-CADUI Proceedings of the 9th International Conference on Intelligent User Interfaces (pp.6-13). New York.

Ghare-Khani, A. \& Khaledian, M. (2009). Implementation of learning skills in intelligent students with learning disabilities. Journal of Exceptional Education Strategies, 91, 10-23.

Gustafson, S., Fälth, L., Svensson, I., Tjus, T., \& Heimann, M. (2011). Effects of three interventions on the reading skills of children with reading disabilities in grade 2 . Journal of Learning Disabilities, 44(2), 123-135.

Karimi, Y. (2010). Learning disabilities: An introduction of theoretical and practical principles alongside with psychological case studies. Tehran: Saravane.

Kennedy, M. J., Deshler, D. D., \& Lloyd, J. W. (2013). Effects of multimedia vocabulary instruction on adolescents with learning disabilities. Journal of Learning Disabilities. doi: 0022219413487406.

Ketamo, H. \& Suominen, M. (2010). Learning-by-teaching in educational game: Educational outcome, user experience and social networks. Journal of Interactive Learning Research, 21(2), 237-255. 
Khana, T. M. (2010). The effects of multimedia learning on children with different special education needs. Procedia Social and Behavioral Sciences, 2, 4341-4345. Available online at www.sciencedirect.com.

Kim, B., Park, H., \& Baek, Y. (2009). Not just fun, but serious strategies: Using meta-cognitive strategies in game-based learning. Computers \& Education, 52, 800-810.

Learner, J. (1997). Learning disabilities: An introduction of theories, strategies and methodologies (Trans. E. Danesh). Tehran: Shahid Beheshti University Publishing.

Leutner, D. (2014). Motivation and emotion as mediators in multimedia learning. Learning and Instruction, 29, 174-175.

Magnan, A. \& Ecalle, J. (2006). Audio-visual training in children with reading disabilities. Computers \& Education, 46(4), 407-425.

Malekian, F. \& Akhundi, A. (2010). The effects of educational multimedia in dictation improvement of exceptional students with dictation difficulty. Journal of Modern Thoughts in Education, 6(1), 145-162.

Mayer, R. E. (2001). Multimedia learning. New York: Cambridge University Press.

Mayer, R. E. (2005). Cognitive theory of multimedia learning: The Cambridge handbook of multimedia learning. New York: Cambridge University Press.

Mioduser, D., Tur-Kaspa, H., \& Leitner, I. (2000). The learning value of computer-based instruction of early reading skills. Journal of Computer Assisted Learning, 16(1), 54-63.

Moreno, R. (2006). Learning with high tech and multimedia environments. Current Directions in Psychological Science, 15, 63-67.

Science, 15, 63-67.National Joint Committee on Learning Disabilities. (1980). Retrieved 198006-01. from www.Idonline.org/njcld

National Research Center on Learning Disabilities (NRCLD) . (2010). Retrieved 2010-05-01. from: www.nrcld.org/about/research/states/section4.html.

Pivec, P. \& Pivec, M .(2011). Digital games: Changing education, one raid at a time. International Journal of Game-Based Learning, 1(1), 1-18.

Ramzani, M. (2000). The effects of reconstructive programs on improvement of students' learning disabilities in mathematics in the third grade of primary schools of Gachsaran County (Unpublished master's thesis). University of Tehran, Faculty of Psychology and Education.

Savari, K. (2008). The study of learning disabilities and educational coping strategies in dictation. Journal of Exceptional Education, 79, 36-45.

Tamjid-Tash, E. (2011). The study of social games and computer games on children's growth. Paivand Magazine, 385, 38-41.

van Daal, V.H.P. \& van der Leij, A. (1992). Computer-based reading and spelling practice for children with learning disabilities. Journal of Learning Disabilities, 25(3),186-195.

Correspondence: Saeed Mousavipour, Ph.D., Faculty of Educational Science and Psychology, Arak University, Arak, Iran 